\title{
Üst gastrointestinal sistem kanaması ile gelen Hirschprung hastası: Olgu Sunumu
}

\section{A Hirschsprung patient admitted with upper gastrointestinal bleeding: case report}

Haşim NAR ${ }^{1}$, Ahmet UYANIKOĞLU ${ }^{1}$, Timuçin AYDOĞAN ${ }^{1}$, Mustafa AKDEMİR ${ }^{2}$, Necati YENICE ${ }^{1}$

${ }^{1}$ Harran Üniversitesi Tip Fakültesi, Gastroenteroloji Bilim Dall, Sanlıurfa

${ }^{2}$ Balıklıöl Devlet Hastanesi, Iç Hastalıkları Kliniği, Şanlıurfa

Üst gastrointestinal kanama gastrointestinal sistemin en sık görülen acillerindendir. Peptik ülser en sık sebeptir. Hirschsprung hastalığı sindirim sisteminin distal kısımlarında sinir pleksuslarında nöronal hücre yokluğuyla tanımlanan konjenital bir hastalıktır. Hastaların \%80'inde rektum ve sigmoid kolon, bazı olgularda daha yaygın tutulum vardır. Neonatal dönemde meydana gelen alt gastrointestinal sistem obstrüksiyonlarında ya da bazı olgularda erken çocukluk çağında uzamış ağır kabızlık durumlarında Hirschprung hastalı̆̆ından şüphelenilir. Burada hematemez şikayeti ile gelen, duodenal ülsere bağlı üst gastrointestinal kanama tespit edilen 52 yaşında, erkek Hirschprung hastası sunulmuştur.

Anahtar kelimeler: Üst gastrointestinal kanama, Hirschprung

\section{GİRIŞ}

Üst gastrointestinal kanama (ÜGK), Treitz ligamentine kadar olan proksimal duodenum ile üst özofagus sfinkteri arasında lümen içine olan kanamayı ifade eder. Şiddeti; subklinik gizli bir kanamadan abondan kanamaya, kronik anemiden akut hipovolemik şoka kadar değişebilen geniş bir spektrumu kapsar (1). Akut ÜGK, sık karşılaşılan önemli mortalite ve morbidite nedenlerindendir. Insidansı yıllık hastane başvurularının 100000'de 50-150'si arasında değişmektedir (2,3). Farmakolojik ve girişimsel tedavi yöntemlerindeki tüm gelişmelere rağmen mortalite \%2-10 arasındadır $(4,5)$. ÜGK'ların yaklaşık \%50'sinin nedeni peptik ülserdir. Hastaların \%30-50'sinde nonsteroid antiinflamatuvar ilaç (NSAII) kullanımı mevcuttur. Özellikle yaşlı hastalarda NSAII'lara bağlı ÜGK riski yüksektir $(6,7)$.

Hirschsprung hastalığı sindirim sisteminin distal kısımlarında sinir pleksuslarında nöronal hücre yokluğuyla tanımlanan konjenital bir hastalıktır. Hastalık \%80 rektum ve sigmoid kolonu, bazı olgularda daha yaygın kısmı etkiler. Neonatal dönemde meydana gelen alt gastrointestinal sistem obstrüksiyonlarında ya da bazı olgularda erken çocukluk çă̆ında uzamış kabızlık durumlarında Hirschprung hastalığından şüphelenilir. Tanısı submukozayı da içeren rektal biyopsi ile konur. Tedavisi genellikle normal olarak inerve edilen barsak
Upper gastrointestinal bleeding is the most common gastrointestinal emergency. Peptic ulcer is the most common cause. Hirschsprung disease is defined by the congenital absence of neuronal cells in the nerve plexuses in the distal part of the digestive tract. The disease affects the rectum and sigmoid colon in $80 \%$ of cases, or is more extensive. Hirschsprung disease is suspected in cases of low gastrointestinal obstruction in the neonatal period, or in cases of chronic severe constipation in childhood. We report a 52-year-old male Hirschsprung patient who admitted with hematemesis due to duodenal ulcer in upper gastrointestinal bleeding.

Keywords: Upper gastrointestinal bleeding, Hirschsprung

segmentinin anal kanala anastomozudur (8). Hastalığın genel popülasyondaki insidansı 1/5000 olup, erkeklerde 4 kat daha sık görülür. Genellikle infant döneminde veya çocukluk çağında tanınan bu hastalıkta 5 yaşından sonra tanı alan olgu sayısı oldukça azdır. Erişkinde Hirschsprung hastalığının görülmesi ise oldukça nadirdir ve bu olgular Hirschsprung hastalığı tanısının akla gelmemesinden dolayı genelde yanlış tanı alırlar (9). Biz üst gastrointestinal kanama ile gelen erişkin bir Hirschprung hastasinı sunduk.

\section{OLGU}

Hematemez şikayeti ile acil servise başvuran 52 yaşında erkek hastanın boyu: $168 \mathrm{~cm}$, kilosu: $65 \mathrm{~kg}$, vücut kitle indeksi: $23 \mathrm{~kg} / \mathrm{m}^{2}$ olarak ölçüldü. Fizik muayenede tansiyon arteryel: 100/60 mmHg, nabız: 90/dk, karında sağ üst kadrandan inguinale kadar uzanan, karnın orta hatta kadar yarısını dolduran, perküsyonla yer yer submatite, yer yer sonorite alınan, ele gelen kitle mevcuttu. Rektal tuşede melena saptanmadi. Yapılan tetkiklerde kanda, hemoglobin: 8,6 gr/dl, lökosit: 9160/ $\mathrm{mm}^{3}$ ve trombosit: $226000 / \mathrm{mm}^{3}$, üre:89 mg/dl, kreatinin: $0.58 \mathrm{mg} / \mathrm{dl}$ olarak saptanan hastaya yapilan gastroskopide antrumu dolduran beklemiş kan ve pihtı görüldü. 
Hasta klinik izleme alındı. Oral alımı kesilen hastaya, 2 ünite eritrosit süspansiyonu, $8 \mathrm{mg} / \mathrm{saat}$ proton pompa inhibitörü (esomeprazol) infüzyonu verildi, vital bulguları ve hemogram takibi yapıldı. Takipte hematemez şikayeti tekrarlamadı. Vital bulguları ve hemogramı stabil seyretti. Ele gelen kitle nedeniyle yapılan batın ultrasonografisinde yoğun gaz nedeniyle net değerlendirme yapılamayan hastaya çekilen batın tomografisinde kolon segmentlerinin ileri derecede dilate olduğu görüldü (Resim 1). Hastanın sorgulamasında yaklaşık 2 yaşında başlayan uzamış kabızlık (ortalama ayda bir dışkılama) olduğu öğrenildi. Hasta çocukluk çağında barsaktan biyopsi yapılarak bağırsak hastalığı olduğunu belirtti. Hastaya operasyon önerildiği ve kabul etmediği öğrenildi. Yatışının 3. gününde gastroskopisi tekrarlanan hastanın duodenumun ön yüzde yaklaşık 1 cm'lik (Resim 2) ve apekste 0.5 cm'lik, ortası nekrotik, etrafı kabarık, 2 adet Forrest 3 ülser görüldü

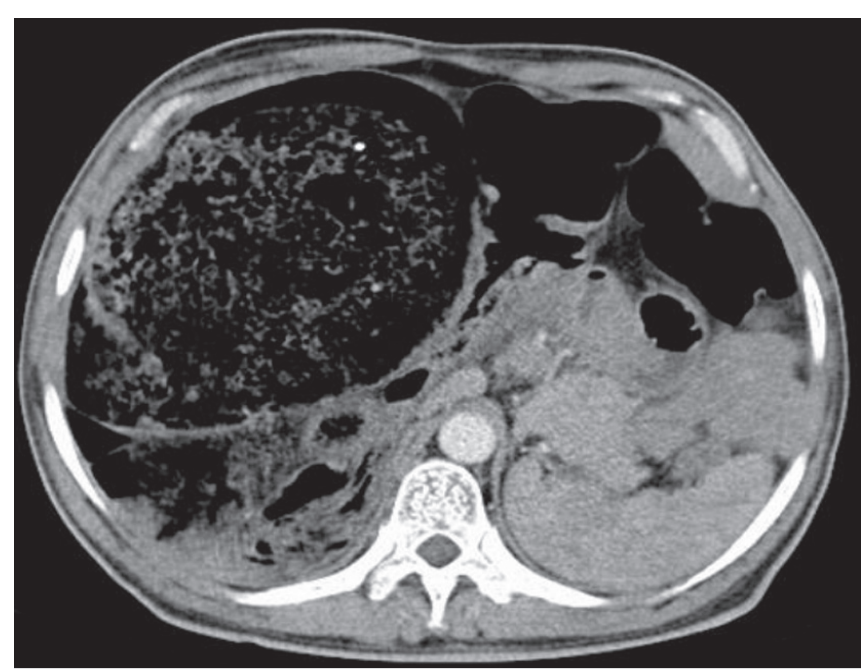

Resim 1: Bilgisayarlı tomografide olgunun genişlemiş kolon segmenti görülmekte

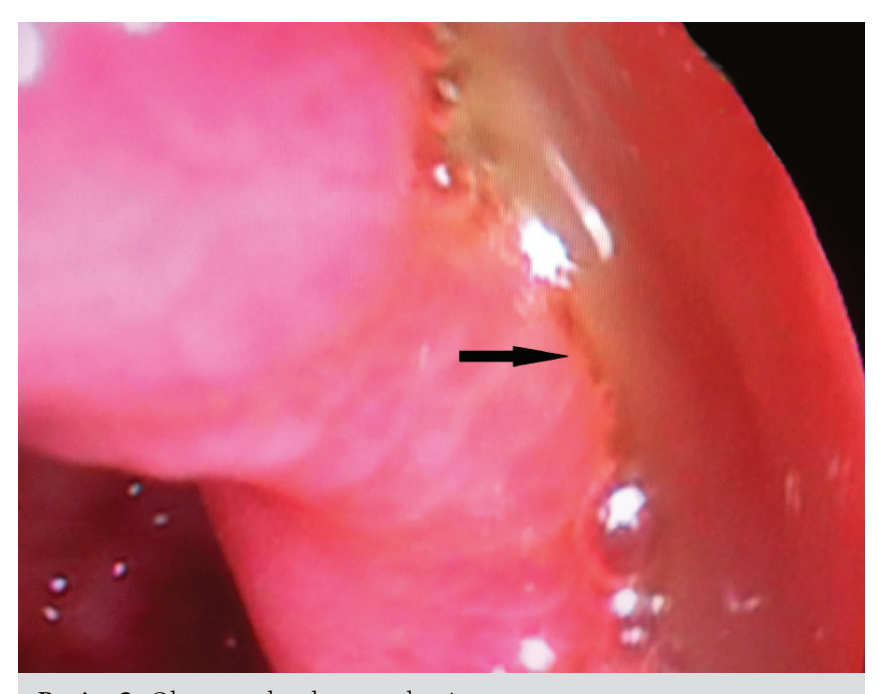

Resim 2: Olgunun duodenum ülseri ve kanama odağı olarak bu ülserler düşünüldü. Hasta çıkış tedavisi düzenlenerek poliklinik takibine gelmek üzere taburcu edildi.

\section{TARTIŞMA}

Üst gastrointestinal kanama (ÜGK), Treitz ligamentine kadar olan proksimal duodenum ile üst özofagus sfinkteri arasında lümen içine olan kanamayı ifade eder. Şiddeti; subklinik gizli bir kanamadan abondan kanamaya, kronik anemiden akut hipovolemik şoka kadar değişebilen geniş bir spektrumu kapsar (1). Bizim hastamızda vital bulgularda bozulmaya yol açmayan ve kisa süreli takipte stabilleşen bir kanama mevcuttu. ÜGK'ların yaklaşık \%50'sinin nedeni peptik ülserdir $(6,7)$ ve bizim hastamizda da kanamanın nedeni duodenal ülser olarak saptandl.

Ülkemizde yapılmış bir çalışmada ÜGK ile gelen hastaların \%17'si hematemez, \%37.8'i hematemez ve melena, \%45.2'si melena ile başvurmuştur (10). Hastamız hematemez ile müracaat etmişti, melena şikayeti yoktu ve tuşede melena saptanmamıştı. Başlangıçta melenaya firsat vermeyen abondan varis kanaması olabileceği düşünüldü, ancak gastroskopisinde varis yoktu, mide yoğun beklemiş kan ile dolu idi. Fizik muayenede karında kitle, anamnezle tekrar sorgulanınca ayda bir kez dişkılama hikayesi ve bilgisayarlı tomografide geniş barsak ansları hastada Hirschprung hastalığını düşündürttü ve melena olmaması buna bağlandı.

Hirschsprung hastalığı sindirim sisteminin distal kısımlarında sinir pleksuslarında nöronal hücre yokluğuyla tanımlanan konjenital bir hastalıktır. Hastaların \%80'inde rektum ve sigmoid kolon tutulumu, bazı olgularda daha yaygın tutulum vardır. Neonatal dönemde meydana gelen alt gastrointestinal sistem obstrüksiyonlarında ya da bazı olgularda erken çocukluk çağında uzamış kabızlık durumlarında Hirschprung hastalığından şüphelenilir. Tanısı submukozayı da içeren rektal biyopsi ile konur. Tedavisinde genellikle normal olarak inerve edilen barsak segmentinin anal kanala anastomozu uygulanır (8). Bizim hastamızda da erken çocukluk çağında ortaya çıkan uzamış kabızlık şikayeti mevcuttu. Hasta dış merkezde çocukluk çağında bağırsağından biyopsi alındığını ve kabızlığına neden olan doğumsal bir hastalığı olduğunu tariflediğinden öykü, klinik bulgular ve görüntüleme yöntemlerine dayanılarak Hirschprung hastalığı düşünüldü. Hastalık erkeklerde 4 kat fazla görülürken (9) bizim hastamız da erkekti. Hirschsprung hastalığında, ganglion hücrelerinin yokluğu sonucunda rektoanal inhibitör refleks etkilenen segmentte kaybolur ve ilgili segment kontrakte olarak kalır. Aganglionik segmentin kalıcı kontraksiyonu sonucu daha proksimaldeki segment ise dilate olur $(11,12)$. Bizim hastamızın da radyolojik görüntülemesinde kolondaki dilatasyon belirgindi.

Sonuç olarak Hirschprung hastalığı neonatal ve erken çocukluk çağında ortaya çıkan bir hastalık olmasına rağmen, 
bu hastalar ileri yaşta başka hastalıklar nedeniyle müracaat edebilir ve uzamış kabızlık şikayeti olan hastalarda akla gelmelidir. Hastamızda üst gastrointestinal sistem kanaması ol-

\section{KAYNAKLAR}

1. Yamada T. Handbook of Gastroenterology. Philadelphia. Lippincott Williams \& Wilkins 2002;16-8.

2. Longstreth GF. Epidemiology of hospitalization for acute upper gastrointestinal haemorrhage: a population based study. Am J Gastroenterol 1995;90:206-10.

3. Paspatis GA, Matrella E, Kapsorikatis A, et al. An epidemiological study of acute upper gastrointestinal bleeding in Crete, Greece. Eur J Gastroenterol Hepatol 2000;12:1215-20.

4. Mungan Z. Üst gastrointestinal sistem kanamaları. In: Ökten A, editor Gastroenterohepatoloji. Nobel Tip Kitabevleri 2001;75.

5. Uyanıkoğlu A, Aksoy Ö, Avcı S, et al. Üst gastrointestinal sistem kanamalı hastalarımızın değerlendirilmesi. Vakıf Gureba Eğitim Hastanesi Dergisi 2007:5:17-20.

6. Hernandez-Diaz S, Garcia Rodriguez LA. Association between nonsteroidal anti-inflammatory drugs and upper gastrointestinal tract bleeding/perforation: an overview of epidemiologic studies published in the 1990s. Arch Intern Med 2000;160:2093-9. masına rağmen melena olmaması, anamnezde ayda bir kez dışkılama şeklinde tarif edilen sürekli kabızlık, muayenede karında kitle ve bilgisayarlı tomografi ile tanı konulmuştur.

7. Uyanıkoğlu A, Danalıoğlu A, Davutoğlu C, et al. Akut üst gastrointestinal sistem kanaması: endoskopi sonuçlarının retrospektif değerlendirmesi. J Ist Faculty Med 2008;71:120-3.

8. Boman F, Corsois L, Paraf F. Hirschsprung's disease: practical considerations. Ann Pathol 2004;24:486-98.

9. Chen F, Winston JH III, Jain SK, et al. Hirschsprung's disease in a young adult: report of a case and review of the literature. Ann Diagn Pathol 2006;10:347-51.

10. Okutur SK, Alkım C, Bes C, et al. Akut üst gastrointestinal sistem kanamaları: 230 olgunun analizi, Akademik Gastroenteroloji Dergisi 2007;6:30-6.

11. de Lorijin F, Boeckxstaens GE, Benninga MA. Symtomatology, pathophysiology, diagnostic workup, and treatment of Hirschsprung disease in infancy and childhood. Pediatr Gastroenterol 2007;9:245-53.

12. Wheatley MJ, Wesley JR, Coran AG, Polley TZ Jr. Hirschsprung's disease in adolescents and adults. Dis Colon Rectum 1990;33:622-9. 